\title{
Quality of life in panic disorder: the influence of clinical features and personality traits
}

\author{
Qualidade de vida no transtorno de pânico: a influência de características \\ clínicas e traços de personalidade
}

\author{
Marcos Fidry, (i) Morena Mourao Zugliani, (D) Clarissa Reis do Valle, Renan Machado Martins, \\ Mariana Costa do Cabo, (1) Antonio Egidio Nardi, Rafael Christophe Freire
}

\begin{abstract}
Objective: To identify which clinical features and personality traits are associated with quality of life (QoL) in panic disorder (PD) patients.

Methods: This was a cross-sectional study with PD patients. The brief version of the World Health Organization Quality of Life Questionnaire (WHOQOL-BREF) and the Big Five Inventory (BFI) were used to assess QoL and personality traits respectively. The strength of correlations was measured with Pearson's, Spearman's, and point-biserial correlation coefficients. We also performed multiple linear regressions, considering sociodemographic data and scores from clinical scales as independent variables and QoL scores as dependent variables.

Results: A total of 98 patients were evaluated. Depressive symptoms had a strong negative correlation with $\mathrm{QoL}$ and, to a lesser extent, panic and anxiety symptoms were also negatively correlated with QoL. While consciousness, extraversion, and agreeableness had mild positive correlations with QoL, neuroticism had a strong negative correlation.

Conclusion: Symptoms of depression, anxiety, and panic seem to have a negative impact on the QoL of PD patients. Personality traits, especially neuroticism, may also influence QoL in these patients.
\end{abstract}

Keywords: Panic disorder, quality of life, personality inventory, major depressive disorder, neuroticism.

\section{Resumo}

Objetivo: Identificar quais características clínicas e traços de personalidade são mais associados à qualidade de vida (QdV) em pacientes com transtorno de pânico (TP).

Métodos: Este foi um estudo transversal, realizado em pacientes com TP. A versão breve do Questionário de Qualidade de Vida da Associação Mundial de Saúde (World Health Organization Quality of Life Questionnaire - WHOQOL-BREF) e o Inventário dos Cinco Grande Fatores (Big Five Inventory - BFI) foram utilizados para avaliar QdV e traços de personalidade, respectivamente. A força de associação foi medida através da correlação de Pearson, de Spearman ou ponto bisserial. Foram também realizadas regressões lineares múltiplas, considerando os dados sociodemográficos e escores obtidos nas escalas clínicas como variáveis independentes, e os escores de QdV como variáveis dependentes.

Resultados: Um total de 98 pacientes foram avaliados. Sintomas depressivos apresentaram uma forte relação negativa com QdV; em menor intensidade, sintomas de TP e ansiosos também se correlacionaram com QdV. Nos domínios de personalidade, enquanto conscienciosidade, extroversão e amabilidade apresentaram uma leve correlação positiva com QdV, neuroticismo apresentou forte correlação negativa.

Conclusão: Sintomas depressivos, ansiosos e de TP parecem ter forte impacto negativo na QdV dos pacientes com TP. Traços de personalidade, principalmente neuroticismo, podem influenciar QdV nesses pacientes.

Descritores: Transtorno de pânico, qualidade de vida, inventário de personalidade, transtorno depressivo maior, neuroticismo.

Laboratório de Pânico e Respiração, Instituto de Psiquiatria, Universidade Federal do Rio de Janeiro (UFRJ), Rio de Janeiro, Brazil. Preliminary results were presented as a poster on Congress on Brain, Behavior and Emotions 2018, on June $23,2018$.

Submitted Aug 17 2018, accepted for publication Apr 022019.

Suggested citation: Fidry M, Zugliani MM, do Valle CR, Martins RM, Cabo MC, Nardi AE, et al. Quality of life in panic disorder: the influence of clinical features and personality traits. Trends Psychiatry Psychother. 2019;41(4):387-393. http://dx.doi.org/10.1590/2237-6089-2019-0008 


\section{Introduction}

Panic disorder (PD) is an anxiety disorder ${ }^{1}$ known for its negative impact on patients' quality of life (QoL), ${ }^{2}$ independently of other factors. ${ }^{3}$ Major depressive disorder (MDD) is a common comorbidity $(55.6 \%$ in lifetime) ${ }^{4}$ which also has an impact on QoL. ${ }^{5}$ Comorbidity with PD increases depression severity, further affecting QoL. ${ }^{6}$ Assessment of QoL has increasingly been used as an outcome measure in clinical trials, in effectiveness studies, in health technology assessments, and in epidemiological surveys to assess the subjective health and well-being of the population. ${ }^{7}$

Previous studies have shown the effect of PD on these domains, mainly on psychological and physical domains. ${ }^{8,9}$ It has also been demonstrated that successful treatment of PD is associated with improvements in QoL. ${ }^{10}$ Other factors may impact QoL. such as PD subtype. For example, non-respiratory subtype (NR) patients had worse psychological QoL than respiratory subtype (RS) patients. ${ }^{11}$ The RS is one of the PD subtypes described by Briggs et al. ${ }^{12}$ Respiratory subtype patients are more likely to have a family history of PD and have higher comorbidity rates for depressive disorders, longer illness duration, and low neuroticism scores. ${ }^{13}$ These patients also score higher on PD severity scales and improvement with pharmacological treatment is observed more quickly than in patients without this subtype. ${ }^{12,14}$

Personality traits are also associated with anxiety and mood disorders and are probably risk factors for PD. ${ }^{15}$ The Five Factor Model, also known as the Big Five Inventory (BFI), is one of the personality models most used in clinical research. This model includes five personality dimensions: extraversion, agreeableness, conscientiousness, neuroticism, and openness to experience. ${ }^{16}$ Many studies have demonstrated that PD, agoraphobia, social anxiety disorder, simple phobia, and MDD are associated with high neuroticism. ${ }^{17-19}$ Agoraphobia is also correlated with low extraversion. ${ }^{18,19}$ There is evidence indicating that high neuroticism and low extraversion are stable personality traits overall, independent of phase of PD treatment. ${ }^{20}$ PD patients without comorbidities have very similar neuroticism and extraversion scores to healthy patients, while patients with many comorbidities have high neuroticism and low extraversion scores. ${ }^{21}$ Personality traits may influence the QoL of healthy subjects, as well as the QoL of psychiatric conditions ${ }^{22-24}$ High neuroticism seems to affect QoL negatively, while high extraversion may influence QoL positively. ${ }^{23}$

Carrera et al. ${ }^{23}$ demonstrated that depression, anxiety, and panic symptoms also influenced QoL in PD patients, but they did not take the effect of personality traits into account. In a study by Hollifield et al., ${ }^{24} \mathrm{QoL}$ of PD patients was influenced by personality traits and a diagnosis of comorbid MDD, but the severity of depression, anxiety, or panic symptoms were not assessed.

The studies mentioned above showed that different clinical features and personality traits affect the QoL of PD patients. ${ }^{22-24}$ However, no studies were found that compared QoL domains with clinical features, the clinical severity of PD, and personality traits. Since the RS of PD has higher scores on panic symptoms scales, ${ }^{13}$ it should also have a greater impact on QoL than other subtypes, but the only study that has evaluated these patients showed the opposite. ${ }^{11}$

The aim of this study is to ascertain whether personality traits, severity of anxiety and depression symptoms, sociodemographic variables, PD subtype, and their interactions affect the QoL of PD patients. We also intend to evaluate the effect size of each of these variables on QoL.

\section{Methods}

This was a cross-sectional study with PD patients who were seeking treatment at the anxiety and depression clinic affiliated with Instituto de Psiquiatria, Universidade Federal do Rio de Janeiro (UFRJ), in Brazil. This study was designed in accordance with the principles of the Helsinki Declaration and approved by the local ethics committee. All patients provided written consent.

The clinic has a trial service, where one psychiatrist and one psychologist evaluate whether patients meet criteria for PD. In the first assessment, all patients were evaluated with the MINI v.4.417. Diagnoses were confirmed in a clinical interview with an expert psychiatrist.

Inclusion criteria were: patients with confirmed diagnosis of PD, age from 18 to 60 years, and not on current pharmacological treatment or in cognitive behavioral therapy (CBT). Exclusion criteria were: illiterate patients and patients with psychotic symptoms, severe personality disorders, intellectual impairment, and/or severe clinical or neurological diseases.

Instruments included a semi-structured questionnaire designed to collect sociodemographic data for this study. Patients were asked if they received previous treatments, if they had any relapses, and how many, and if they received previous CBT. Anxiety severity was measured using the Beck Anxiety Inventory (BAI). ${ }^{25}$ Depressive symptoms were assessed with the Beck Depression Inventory (BDI). ${ }^{26}$ Patients' current PD 
severity was assessed using the Panic and Agoraphobia Scale (PAS), ${ }^{27}$ Clinical Global Impression (CGI) ${ }^{28}$ and Diagnostic Symptom Questionnaire (DSQ). Quality of life was evaluated with the abbreviated version of the World Health Organization Quality of Life Questionnaire (WHOQOL-BREF), ${ }^{29}$ which has been validated in many languages, including Portuguese. ${ }^{30}$ Personality evaluations were conducted with the Big Five Inventory. ${ }^{31}$ All scales were administered at the first interview, while patients weren't receiving any treatment.

The BAI is a self-administered questionnaire with 21 items designed to assess the severity of anxiety symptoms in adult psychiatric populations. Its score ranges from 0 to 63 , with a higher score denoting a more severe degree of anxiety. The BDI is also a self-administered questionnaire, with a score ranging from 0 to 63 and higher scores indicate more severe depression symptoms. The PAS is a 13-item scale on which every item ranges from 0 to 4 and the total sum (0-52) indicates the severity of PD, with a higher score denoting a more severe degree of anxiety. Panic attack symptoms were assessed with DSQ, a list of 13 PA symptoms adapted from DSM-IV in which the presence and level of discomfort of each panic symptom experienced is rated on a 0 (none) to 4-point (very severe) scale, and the total score ranges from 0 to 52. Respiratory symptoms (fear of dying, chest pain/discomfort, shortness of breath, paresthesia, and feelings of choking) during panic attacks were measured and patients who had 4 of 5 symptoms were defined as having the RS. ${ }^{12}$ The respiratory ratio ( $R R$ ) was calculated by dividing the respiratory symptom score by the total DSQ score. ${ }^{32}$ The BFI is a 44-item self-reported inventory that measures an individual on the Big Five Factors of personality. Each question refers to one aspect of each personality trait, and answers vary from "strongly disagree" (1 point) to "strongly agree" (5 points). By the end of the inventory, each trait is averaged and receives a dimensional value, converted into a centesimal scale (0-100): extraversion (BFI-E), agreeableness (BFI-A), conscientiousness (BFI-C), neuroticism (BFI-N), and openness to experience (BFI-O). The sums of the results give dimensional values for each personality trait. The WHOQOL-BREF has 4 QoL domains: Physical, Psychological, Social, and Environmental. It also includes two other subjective questions: "How would you rate your quality of life?" (G1) and "How satisfied are you with your health?" (G2). The results of each domain and the 2 questions vary from 0-100, with lower values indicating worse outcomes.

Correlations between two dimensional clinical variables were assessed with Pearson's correlation coefficients or
Spearman's correlation coefficients, depending on the results of normality testing (Shapiro-Wilk). Point-biserial correlation coefficients were used for dimensional vs. dichotomous variables. We also performed multiple linear regressions, considering sociodemographic data, scores from BDI, BAI, CGI, and PAS as independent variables and QoL scores as dependent variables. We used the Statistical Package for the Social Sciences (SPSS), version 12.0, to perform tests. All analyses were two-tailed and statistical significance was set at $5 \%$. Sample size was calculated using the online calculator from the Clinical and Translational Science Institute at the University of California San Francisco (http://www.sample-size.net/ correlation-sample-size/). The Beta value used was 0.2 and the $r$ value was 0.3 .

\section{Results}

We recruited 98 patients with PD diagnoses. This was an adequate number, since the total sample size calculated for the correlation was 85. Demographic and clinical features are described in Tables 1 and 2 . The statistical analysis is summarized in Tables 3 and 4 .

Table 1 - Social, demographic, and clinical features

\begin{tabular}{lc}
\hline & $\mathbf{n}=\mathbf{9 8}$ \\
\hline Gender & 26 \\
Male & 72 \\
Female & \\
Marital status & \\
Married & 35 \\
Unmarried & 63 \\
& \\
Employment & \\
Employed & 45 \\
Unemployed & 53 \\
& \\
Comorbidity & \\
MDD (current) & 56 \\
MDD (previous episode) & 5 \\
Agoraphobia & 74 \\
Social anxiety disorder & 9 \\
Obsessive compulsive disorder & 7 \\
General anxiety disorder & 35 \\
& \\
Number of previous treatments & \\
First treatment & \\
1 & \\
2 & \\
3 or more & 29 \\
\hline
\end{tabular}

MDD = major depressive disorder. 
Table 2 - Social, demographic, and clinical features

\begin{tabular}{lcc}
\hline & Mean & SD \\
\hline Age & 38.4 & 11.5 \\
Years in education & 13.05 & 3.6 \\
Income (multiples of minimum wage) & 4.7 & 3.9 \\
Age at onset of panic disorder (years) & 35.9 & 12.4 \\
Age at onset of comorbidity (years) & 30.5 & 12.4 \\
Clinical Global Impression (CGI) & 4.8 & 0.9 \\
Panic and Agoraphobia Scale (PAS) & 28.3 & 7.7 \\
Beck Anxiety Inventory (BAI) & 37.1 & 13.1 \\
Beck Depression Inventory (BDI) & 25.1 & 10.8 \\
Respiratory ratio & 0.38 & 0.1 \\
WHOQOL (G1) & 49.2 & 26.0 \\
WHOQOL (G2) & 32.4 & 23.0 \\
WHOQOL (Physical) & 37.2 & 16.8 \\
WHOQOL (Psychological) & 41.2 & 18.9 \\
WHOQOL (Social) & 47.3 & 22.2 \\
WHOQOL (Environmental) & 45.1 & 14.3 \\
BFI-E & 49.5 & 18.1 \\
BFI-A & 63.5 & 16.0 \\
BFI-C & 56.9 & 18.5 \\
BFI-N & 70.6 & 17.6 \\
BFI-O & 67.1 & 18.0 \\
\hline
\end{tabular}

$\mathrm{BFI}=$ Big Five Inventory; SD = standard deviation; WHOQOL = World Health Organization Quality of Life Questionnaire

Table 3 - Statistical correlations

\begin{tabular}{|c|c|c|c|c|c|c|c|c|c|c|c|c|}
\hline & \multicolumn{2}{|c|}{ G1 } & \multicolumn{2}{|c|}{ G2 } & \multicolumn{2}{|c|}{ Physical } & \multicolumn{2}{|c|}{ Psychological } & \multicolumn{2}{|c|}{ Social } & \multicolumn{2}{|c|}{ Environmental } \\
\hline & C & $\mathbf{P}$ & C & $\mathbf{P}$ & C & $\mathbf{P}$ & C & $\mathbf{P}$ & C & $\mathbf{P}$ & C & $\mathbf{P}$ \\
\hline Female gender & -0.04 & 0.695 & -0.008 & 0.940 & 0.052 & 0.614 & -0.264 & 0.009 & -0.133 & 0.193 & -0.164 & 0.106 \\
\hline Income & 0.056 & 0.589 & 0.006 & 0.958 & 0.078 & 0.452 & -0.011 & 0.915 & -0.091 & 0.379 & 0.244 & 0.017 \\
\hline Education (years) & -0.272 & 0.007 & -0.087 & 0.392 & 0.097 & 0.344 & -0.226 & 0.026 & -0.170 & 0.094 & 0.034 & 0.741 \\
\hline Employed & -0.163 & 0.110 & -0.296 & 0.003 & 0.113 & 0.266 & 0.035 & 0.734 & 0.001 & 0.992 & 0.019 & 0.854 \\
\hline Relapses & -0.053 & 0.609 & -0.145 & 0.156 & 0.012 & 0.905 & -0.200 & 0.051 & -0.398 & $<0.001$ & 0.002 & 0.983 \\
\hline Current MDD & -0.225 & 0.026 & -0.148 & 0.147 & -0.273 & 0.007 & -0.359 & $<0.001$ & -0.383 & $<0.001$ & -0.224 & 0.027 \\
\hline Recurrent MDD & -0.170 & 0.095 & -0.123 & 0.216 & -0.263 & 0.009 & -0.238 & 0.019 & -0.224 & 0.026 & -0.101 & 0.321 \\
\hline Agoraphobia & -0.292 & 0.004 & -0.127 & 0.214 & -0.160 & 0.116 & -0.237 & 0.020 & -0.139 & 0.171 & -0.107 & 0.294 \\
\hline OCD & -0.222 & 0.028 & -0.133 & 0.193 & -0.159 & 0.118 & -0.170 & 0.096 & -0.116 & 0.255 & -0.140 & 0.170 \\
\hline GAD & -0.081 & 0.429 & 0.108 & 0.291 & 0.027 & 0.790 & -0.151 & 0.140 & -0.168 & 0.255 & -0.096 & 0.348 \\
\hline Previous CBT & -0.230 & 0.023 & -0.064 & 0.531 & 0.055 & 0.588 & -0.244 & 0.016 & -0.135 & 0.185 & -0.224 & 0.026 \\
\hline $\mathrm{FH}$ & -0.039 & 0.704 & -0.063 & 0.538 & -0.206 & 0.043 & -0.146 & 0.156 & -0.013 & 0.897 & 0.012 & 0.907 \\
\hline CGI & -0.170 & 0.095 & -0.319 & 0.001 & -0.331 & 0.001 & -0.276 & 0.006 & -0.199 & 0.049 & -0.104 & 0.308 \\
\hline PAS & -0.238 & 0.018 & -0.274 & 0.006 & -0.357 & $<0.001$ & -0.260 & 0.007 & -0.238 & 0.018 & -0.198 & 0.04 \\
\hline BAI & -0.211 & 0.037 & -0.179 & 0.077 & -0.403 & $<0.001$ & -0.311 & $<0.001$ & -0.174 & 0.086 & -0.213 & 0.028 \\
\hline BDI & -0.461 & $<0.001$ & -0.230 & 0.023 & -0.570 & $<0.001$ & -0.726 & $<0.001$ & -0.606 & $<0.001$ & -0.477 & $<0.001$ \\
\hline RS & 0.027 & 0.793 & 0.017 & 0.865 & -0.104 & 0.308 & -0.093 & 0.362 & 0.007 & 0.947 & -0.052 & 0.610 \\
\hline RR & 0.139 & 0.173 & 0.184 & 0.070 & 0.163 & 0.109 & 0.213 & 0.037 & -0.280 & 0.005 & 0.009 & 0.932 \\
\hline BFI-E & 0.181 & 0.075 & 0.017 & 0.865 & 0.171 & 0.078 & 0.243 & 0.012 & 0.162 & 0.111 & 0.147 & 0.130 \\
\hline BFI-A & 0.331 & 0.001 & -0.001 & 0.994 & 0.158 & 0.105 & 0.359 & $<0.001$ & 0.357 & $<0.001$ & 0.239 & 0.013 \\
\hline BFI-C & 0.403 & $<0.001$ & 0.188 & 0.064 & 0.049 & 0.613 & 0.347 & $<0.001$ & 0.405 & $<0.001$ & 0.192 & 0.046 \\
\hline BFI-N & -0.423 & $<0.001$ & -0.160 & 0.116 & -0.341 & 0.001 & -0.351 & $<0.001$ & -0.400 & $<0.001$ & -0.323 & 0.001 \\
\hline BFI-O & 0.015 & 0.886 & -0.012 & 0.903 & 0.041 & 0.686 & 0.022 & 0.831 & -0.039 & 0.705 & 0.025 & 0.806 \\
\hline
\end{tabular}

$\mathrm{BAI}=$ Beck Anxiety Inventory; BDI = Beck Depression Inventory; BFI-A = Agreeableness; BFI-C = Conscientiousness; BFI-E = Extraversion; BFI-N = Neuroticism; $\mathrm{BFI}-\mathrm{O}=$ Openness to Experience; $\mathrm{C}=$ correlation; $\mathrm{CBT}=$ cognitive-behavioral therapy; $\mathrm{CGI}=$ Clinical Global Impression; $\mathrm{FH}=$ family history of panic disorder; $\mathrm{GAD}=$ general anxiety disorder; $\mathrm{MDD}=$ major depressive disorder; $\mathrm{OCD}=$ obsessive-compulsive disorder; $\mathrm{P}=\mathrm{p}$-value; PAS = Panic and Agoraphobia Scale; $\mathrm{RR}=$ respiratory ratio; $R S=$ panic disorder respiratory subtype; SUD = substance dependence. Bold indicates $\mathrm{p}<0.05$. 
Table 3 refers to mean correlations and Table 4 to multiple linear regression.

With regard to QoL, the analysis shows that the best model for the physical domain included BDI, CGI severity, neuroticism, and age at onset of comorbidity. The regression model for the psychological domain included the variables BDI, CGI severity, previous CBT, current major depressive disorder, alcohol abuse, gender, conscientiousness, and agreeableness. The best regression model for the social domain included the variables BDI, number of relapses, neuroticism, and CGI. BDI, family income, and previous CBT were the variables included in the best regression model for the environmental domain of QoL. For the G1 question, the best model included BDI, BFI-N, and years in education. For G2, the best model included CGI, employment, and BDI.

Table 4 - Multiple linear regression

\begin{tabular}{|c|c|c|c|}
\hline \multirow[b]{2}{*}{ Coefficients } & \multicolumn{3}{|c|}{ Multiple linear regression } \\
\hline & $\mathbf{R}^{2}$ & B & $p$ \\
\hline Physical & 0.429 & & \\
\hline BDI & & -0.473 & $<0.001$ \\
\hline CGI & & -0.268 & $<0.001$ \\
\hline BFI-N & & -0.261 & 0.004 \\
\hline $\mathrm{AOC}$ & & -0.179 & 0.045 \\
\hline Psychological & 0.682 & & \\
\hline BDI & & -0.496 & $<0.001$ \\
\hline CGI & & -0.213 & 0.001 \\
\hline Previous CBT & & -0.130 & 0.039 \\
\hline Current MDD & & -0.190 & 0.003 \\
\hline Alcohol abuse & & -0.190 & 0.003 \\
\hline BFI-C & & 0.187 & 0.007 \\
\hline Gender (female) & & -0.156 & 0.012 \\
\hline BFI-A & & 0.130 & 0.045 \\
\hline Social & 0.491 & & \\
\hline BDI & & -0.494 & $<0.001$ \\
\hline Relapses & & -0.302 & $<0.001$ \\
\hline BFI-N & & -0.179 & 0.022 \\
\hline CGI & & -0.151 & 0.042 \\
\hline Environmental & 0.270 & & \\
\hline BDI & & -0.424 & $<0.001$ \\
\hline Income & & 0.214 & 0.018 \\
\hline Previous CBT & & -0.213 & 0.018 \\
\hline G1 Question & 0.321 & & \\
\hline BDI & & -0.341 & $<0.001$ \\
\hline BFI-N & & -0.297 & 0.001 \\
\hline Education (years) & & -0.218 & 0.011 \\
\hline G2 Question & 0.226 & & \\
\hline CGI & & -0.338 & $<0.001$ \\
\hline Employment & & -0.323 & 0.001 \\
\hline BDI & & -0.203 & 0.025 \\
\hline
\end{tabular}

$B=$ beta value; $\mathrm{R}^{2}=$ adjusted root square; $\mathrm{AOC}=$ age at onset of comorbidity; $\mathrm{MDD}=$ major depressive disorder; $\mathrm{CGI}=\mathrm{Clinical}$ Global Impression; BDI = Beck Depression Inventory; $\mathrm{CBT}=$ cognitive-behavioral therapy; $\mathrm{BFI}-\mathrm{A}=\mathrm{Agreeableness}$; $\mathrm{BFI}-\mathrm{C}=$ Conscientiousness; BFI-N = Neuroticism; G1 = general quality of life perception; G2 = general health perception. 


\section{Discussion}

Our results show that our group of PD patients has "moderate" to "markedly ill" disorder severity, with lower QoL values than the average population. ${ }^{33}$ The physical QoL domain was the most impaired. Initially, we had speculated that due to comorbid agoraphobia and depression, the social QoL domain would have the lowest mean, but the social QoL actually had the highest score. One possible explanation is that healthy Brazilian individuals have higher scores for the social domain than for other domains ${ }^{33}$ and therefore Brazilian PD patients exhibit the same QoL pattern with lower scores.

In the current study, the lowest QoL value was observed in the physical domain, because PD symptoms may simulate other medical conditions. Notwithstanding, RS patients with severe cardiac and breathing symptoms ${ }^{13}$ were no different from nonrespiratory subtype patients. In 2009, similar results were observed in a study that was unable to correlate RS patients with the physical QoL domain, although it did report a moderate positive correlation between RS patients and the psychological QoL domain. ${ }^{11}$ The current study could not replicate that finding, since RS was not correlated with any of the QoL domains. However, RR did have a mild positive correlation with the Psychological and Social domains.

Although current MDD diagnosis had mild to moderate correlations with almost all QoL domains, depressive symptoms (BDI) had moderate to strong associations with all QoL domains, which could indicate that the severity of symptoms was more important to QoL than the diagnosis of depression itself. The multiple linear regression analysis showed that depression symptoms were the most important factor influencing all QoL domains in PD patients, demonstrating the magnitude of the effect of depressive symptoms on QoL.

Several different personality traits were associated with QoL in PD patients. It was demonstrated that high neuroticism, low extroversion, and low conscientiousness are correlated with depressive symptoms. ${ }^{34}$ Also, high neuroticism is correlated with anxiety and depressive disorder comorbidity. ${ }^{21,35}$ In 2006, studies demonstrated higher mean scores for neuroticism and lower mean scores for extraversion in comorbid PD and MDD patients. ${ }^{17}$ There is also evidence that high neuroticism scores predict poor prognosis in depressive patients, ${ }^{36}$ although there was no data on PD patients until now. The results showed that in PD patients, BFI-N is a marker of low QoL in all four domains and the G1 question. Agreeableness and consciousness were positively associated with general, psychological, social, and environmental QoL. These findings suggest that personality traits are important factors affecting QoL in PD patients. Longitudinal studies are needed to determine the causality and prognosis of this association.

One curious finding was the negative correlation between previous CBT treatment and general, psychological, and environmental QoL domains. Since CBT is an effective treatment for PD with or without agoraphobia, ${ }^{37}$ with lasting effects, ${ }^{38}$ the opposite effect on QoL was expected. CBT is not widely accessible in our geographic area, and because of this only patients with severe PD have access to this treatment. In our clinical sample, previous CBT may have become a marker for patients with refractory or recurrent PD. Also, the questionnaire administered didn't ask whether patients completed the CBT treatment, only if they had started it. So, patients who didn't complete a CBT treatment could have been included in the statistical analysis, leading to a distorted result.

The findings of the study show that, in PD patients, depressive symptoms are more likely to impact QoL domains than the PD symptoms themselves. Clinicians must be aware of the presence of depressive symptoms (including subclinical depression), rather than only focusing on PD or panic attacks, and treat them incisively, since they can impair these patients' QoL.

One of the main limitations of the current study was the lack of a control group with healthy individuals, which would have allowed us to compare the impact of PD on QoL. Additionally, there are many severe cases in our sample, with more than half of patients with a history of recurrence, and severity and chronicity could also have an impact on QoL. Finally, the neuroticism personality trait can sometimes be mistaken for depression symptoms, thus it is a current possible cause that both are strongly associated with worse QoL.

\section{Conclusion}

Symptoms of depression, anxiety, and panic have a significant negative impact on the QoL of PD patients. Personality traits, especially neuroticism, may also influence QoL in these patients. Depressive symptoms seem to have stronger associations with QoL impairment. Longitudinal studies are needed to better understand the causality and prognosis of QoL in PD patients.

\section{Disclosure}

No conflicts of interest declared concerning the publication of this article. 


\section{References}

1. American Psychiatric Association. Diagnostic and Statistical Manual of Mental Disorders, Fifth Edition (DSM-5). Arlington: American Psychiatric Publishing; 2013.

2. Markowitz JS, Weissman MM, Ouellette R, Lish JD, Klerman GL. Quality of life in panic disorder. Arch Gen Psychiatry. 1989;46:98492.

3. Cramer V, Torgersen S, Kringlen E. Quality of life and anxiety disorders: a population study. J Nerv Ment Dis. 2005;193:196202.

4. Kessler RC, Stang PE, Wittchen HU, Ustun TB, Roy-Burne PP, Walters EE. Lifetime panic-depression comorbidity in the National Comorbidity Survey. Arch Gen Psychiatry. 1998;55:801-8.

5. Ay-Woan P, Sarah CP, Lyinn C, Tsyr-Jang C, Ping-Chuan H. Quality of life in depression: predictive models. Qual Life Res. 2006:15:39-48.

6. IsHak WW, Mirocha J, Christensen S, Wu F, Kwock R, Behjat J, et al. Patient-reported outcomes of quality of life, functioning, and depressive symptom severity in major depressive disorder comorbid with panic disorder before and after SSRI treatment in the star*d trial. Depress Anxiety. 2014;31:707-16.

7. Wilson IB, Cleary PD. Linking clinical variables with health-related quality of life. A conceptual model of patient outcomes. JAMA. 1995;273:59-65.

8. Yen CF, Kuo CY, Tsai PT, Ko CH, Yen JY, Chen TT. Correlations of quality of life with adverse effects of medication, social support, course of illness, psychopathology, and demographic characteristics in patients with panic disorder. Depress Anxiety. 2007; 24:563-70.

9. Kang EH, Kim B, Choe AY, Lee JY, Choi TK, Lee SH. Panic disorder and health-related quality of life: the predictive roles of anxiety sensitivity and trait anxiety. Psychiatry Res. 2015;225:157-63.

10. Heldt $E$, Blaya $C$, Isolan L, Kipper L, Teruchkin B, Otto MW, et al. Quality of life and treatment outcome in panic disorder: cognitive behavior group therapy effects in patients refractory to medication treatment. Psychother Psychosom. 2006;75:183-6.

11. de-Melo-Neto VL, King AL, Valença AM, da Rocha Freire RC, Nardi $A E$. Respiratory and non-respiratory panic disorder subtypes: clinical and quality of life comparisons. Rev Port Pneumol. 2009; 15:859-74.

12. Briggs AC, Stretch DD, Brandon S. Subtyping of panic disorder by symptom profile. Br J Psychiatry. 1993;163:201-9.

13. Zugliani MM, Freire RC, Perna G, Crippa JA, Nardi AE. Laboratory, clinical and therapeutic features of respiratory panic disorder subtype. CNS Neurol Disord - Drug Targets. 2015;14:627-35.

14. Nardi $A E$, Nascimento I, Valença AM, Lopes FL, Mezzasalma MA, Zin WA, et al. Respiratory panic disorder subtype: Acute and long-term response to nortriptyline, a noradrenergic tricyclic antidepressant. Psychiatry Res. 2003;120:283-93.

15. Bienvenu OJ, Stein MB, Samuels JF, Onyike CU, Eaton WW, Nestadt G. Personality disorder traits as predictors of subsequent first-onset panic disorder or agoraphobia. Compr Psychiatry. 2009;50:209-14.

16. Goldberg LR. An Alternative "Description of Personality": The BigFive Factor Structure. J Pers Soc Psychol. 1990;59:1216-29.

17. Freire RC, Lopes FL, Veras AB, Valença AM, Mezzasalma MA, Nascimento I, et al. Personality traits spectrum in panic disorder and major depression. Braz J Psychiatry. 2007;29:31-4.

18. Bienvenu OJ, Brown C, Samuels JF, Liang KY, Costa PT, Eaton WW, et al. Normal personality traits and comorbidity among phobic, panic and major depressive disorders. Psychiatry Res. 2001;102:73-85.

19. Carrera M, Herrán A, Ramírez ML, Ayestarán A, Sierra-Biddle D, Hoyuela $F$, et al. Personality traits in early phases of panic disorder: implications on the presence of agoraphobia, clinical severity and short-term outcome. Acta Psychiatr Scand. 2006;114:417-25.
20. da Rocha Freire RC, Marco MO, Lopes FL, Veras AB, Caldirola D. The Stability of Personality Traits Despite Naturalistic Treatment for Panic Disorder. Ann Depress Anxiety. 2014;1:1-5.

21. Zugliani MM, Martin-Santos R, Nardi AE, Freire RC. Personality Traits in Panic Disorder Patients With and Without Comorbidities. J Nerv Ment Dis. 2017;205:855-8.

22. Gao $T$, Xiang $Y T$, Zhang $H$, Zhang $Z$, Mei S. Neuroticism and quality of life: Multiple mediating effects of smartphone addiction and depression. Psychiatry Res. 2017;258:457-61.

23. Carrera M, Herrán A, Ayuso-Mateos JL, Sierra-Biddle D, Ramírez $M L$, Ayestarán A, et al. Quality of life in early phases of panic disorder: Predictive factors. J Affect Disord. 2006;94:127-34.

24. Hollifield M, Katon W, Skipper B, Chapman T, Ballenger JC, Mannuzza $S$, et al. Panic disorder and quality of life: Variables predictive of functional impairment. Am J Psychiatry. 1997;154:766-72.

25. Beck AT, Epstein N, Brown G, Steer RA. An inventory for measuring clinical anxiety: psychometric properties. J Consult Clin Psychol. 1988;56:893-7.

26. Beck AT, Ward $\mathrm{CH}$, Mendelsom M, Mock J, Erbaugh J. An inventory for measuring depression. Arch Gen Psychiatry, 1961:4:561-71.

27. Bandelow B. Panic and agoraphobia scale (PAS). Seattle: Hogrefe \& Huber Publishers; 1999.

28. Guy W. ECDEU assessment manual for psychopharmacology. Revised ed. [S.I.]: U.S. Department of Health, Education, and Welfare; 1976.

29. Development of the World Health Organization WHOQOL-BREF quality of life assessment. The WHOQOL Group. Psychol Med. 1998;28:551-8.

30. Fleck MP, Louzada S, Xavier M, Chachamovich E, Vieira G, Santos $L$, et al. Aplicação da versão em português do instrumento abreviado de avaliação da qualidade de vida "WHOQOL-bref." Rev Saude Publica. 2000;34:178-83.

31. John OP, Robins RW, Pervin LA. Handbook of personality: theory and research. 3rd ed. New York; London: Guilford; 2008.

32. Freire RC, Nascimento I, Valença AM, Lopes FL, Mezzasalma $M A$, Neto VL de $M$, et al. The panic disorder respiratory ratio: A dimensional approach to the respiratory subtype. Rev Bras Psiquiatr. 2013;35:57-62.

33. Cruz LN, Polanczyk CA, Camey SA, Hoffmann JF, Fleck MP. Quality of life in Brazil: normative values for the WHOQOLbref in a southern general population sample. Qual Life Res. 2011;20:1123-9.

34. Hakulinen $C$, Elovainio $M$, Pulkki-Råback L, Virtanen $M$, Kivimäki M, Jokela M. Personality And Depressive Symptoms: Individual Participant Meta-Analysis of 10 Cohort Studies. Depress Anxiety. 2015;32:461-70.

35. Lamers $F$, van Oppen $P$, Comijs HC, Smit JH, Spinhoven $P$, van Balkom AJ, et al. Comorbidity patterns of anxiety and depressive disorders in a large cohort study: the Netherlands Study of Depression and Anxiety (NESDA). J Clin Psychiatry. 2011;72:3418.

36. Mulder RT. Personality pathology and treatment outcome in major depression: a review. Am J Psychiatry. 2002;159:359-71.

37. McHugh RK, Smits JA, Otto MW. Empirically supported treatments for panic disorder. Psychiatr Clin North Am. 2009;32:593-610.

38. Barlow DH, Gorman JM, Shear MK, Woods SW. Cognitivebehavioral therapy, imipramine, or their combination for panic disorder: A randomized controlled trial. JAMA. 2000;283:252936.

\section{Correspondence:}

Marcos Fidry

Estrada do Galeão, 2500, Bloco A, Sala 215, Portuguesa

21931-582 - Rio de Janeiro, RJ - Brazil

Tel. : +55 (21) 33935311

Fax: +55 (21) 38527669

E-mail: marfidry@gmail.com 